\title{
Falling among people with Parkinson's disease: motor, non-motor, or both?
}

\author{
Risco de quedas em pessoas com a doença de Parkinsons: sintomas motores, sintomas \\ não-motores ou ambos?
}

Ana Ligia SILVA DE LIMA', Carlijn BORM', Nienke M. de VRIES ${ }^{1}$, Bastiaan R. BLOEM ${ }^{1}$

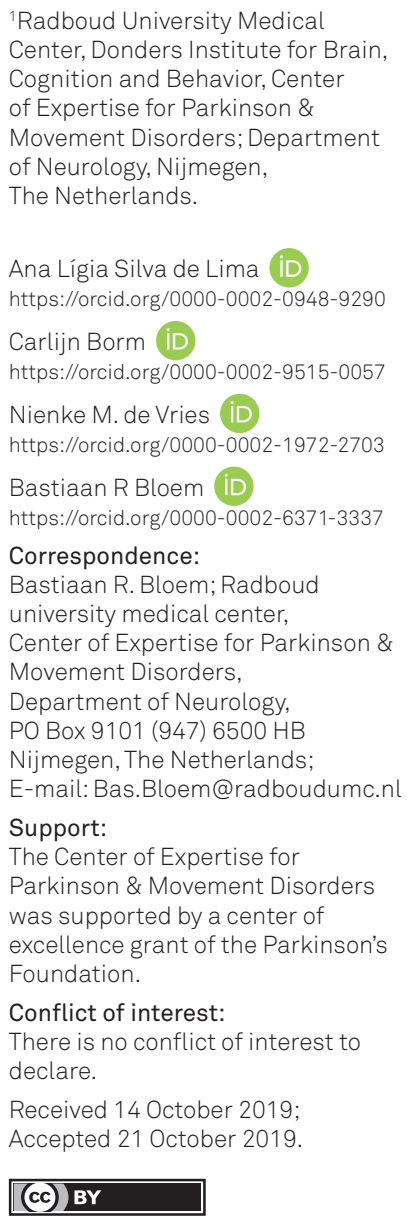

${ }^{1}$ Radboud University Medical Center, Donders Institute for Brain, Cognition and Behavior, Center of Expertise for Parkinson \& Movement Disorders; Department of Neurology, Nijmegen, The Netherlands.

Ana Lígia Silva de Lima (iD https://orcid.org/0000-0002-0948-9290 Carlijn Borm iD

https://orcid.org/0000-0002-9515-0057

Nienke M. de Vries

https://orcid.org/0000-0002-1972-2703

Bastiaan R Bloem iD

https://orcid.org/0000-0002-6371-3337

Correspondence:

Bastiaan R. Bloem; Radboud university medical center,

Center of Expertise for Parkinson \&

Movement Disorders,

Department of Neurology,

PO Box 9101 (947) 6500 HB

Nijmegen, The Netherlands;

E-mail:Bas.Bloem@radboudumc.nl

Support:

The Center of Expertise for

Parkinson \& Movement Disorders

was supported by a center of

excellence grant of the Parkinson's

Foundation.

Conflict of interest:

There is no conflict of interest to

declare.

Received 14 October 2019;

Accepted 21 October 2019

\section{(cc) BY}

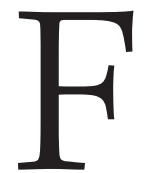

alling is common among people with Parkinson's disease (PD). Because of a common amnesia for falls, capturing falls in real-life is challenging. Despite this challenge, we estimate that about $70 \%$ of PD patients experience at least one fall per year ${ }^{1}$, which - according to objective measurements using wearable falls detectors - is about 1.8 times more often than age matched controls ${ }^{2}$. Established risk factors for falling in PD include particularly motor features, such as freezing of gait or balance impairment ${ }^{3,4}$. The contribution of non-motor symptoms, such as autonomic failure, ophthalmological problems or depression, can be suspected, but is to date much less clear ${ }^{5,6}$.

In this current edition, Alvarado-Bolaños and colleagues report on the association between non-motor symptoms and fall risk in people with PD. Using a cross-sectional design, they collected retrospective data from a convenience sample of 179 people with PD attending a Movement Disorders clinic in Mexico City. Thirty of these were self-reported fallers (16 of whom were recurrent fallers), and their profile was fairly representative (19 men; mean age 66.7 years), although 13 were surprisingly mildly affected (Hoehn \& Yahr stage 1 or 2). Baseline data included presence and severity of motor symptoms (Movement Disorder Society - Unified Parkinson's Disease Rating Scale - MDS-UPDRS) and non-motor symptoms (non-motor symptoms scale - NMSS; and relevant sections of the UPDRS). Bivariate analyses showed that fallers had more non-motor symptoms (mainly in the urinary and miscellaneous domains of the NMSS) compared to non-fallers. However, in a multivariate analysis, non-motor symptoms were no longer predictive of falling; only disease duration and the Postural Imbalance and Gait Disorder (PIGD) type of PD persisted as predictors of falls.

A strength of this study was the explicit focus on a comprehensive range of non-motor symptoms, which were often not addressed in prior falls studies. Indeed, many prior studies purposely (yet wrongly) excluded subjects with e.g. cognitive impairment, so the contribution of cognition as risk factor for falls may well have been underestimated ${ }^{7}$. Other strengths included the relatively large sample size ( $\mathrm{n}=179$ - although the number of actual fallers was rather low) and the structured assessment of all participants. Somewhat surprisingly, the hypothesized association between falls and non-motor symptoms could not be confirmed, in contrast to several other studies that did find supportive evidence ${ }^{5,6}$.

Several methodological choices may explain these findings. First, falling was based on retrospective self-report, so recall bias cannot be excluded. This is particularly vexing since PD patients with the greatest cognitive impairment are conceivable also the one with the highest fall rates. Second, although the NMSS is a validated assessment tool, it provides only a general overview of non-motor symptoms. This scale does not offer an in-depth characterization of the various individual non-motor symptoms, and several potentially relevant non-motor symptoms, such as blurred vision, diminished color or contrast vision and paresthesia are not included in the questionnaire. Unfortunately, the authors did not perform a complementary objective assessment of critical non-motor symptoms such as orthostatic hypotension (using blood pressure measurements after rising, ideally using tilt table testing), visual symptoms (e.g. visual acuity testing) or cognition (using validated scales such as the Montreal Cognitive Assessment). Moreover, there is no description of medication use, other than Parkinson 
medication. Yet, drugs such as benzodiazepines are an important risk factor for falls, also in PD patients ${ }^{8}$. Third, only 30 patients were classified as fallers, so the power may have been too low for detecting significant group differences.

Another important limitation is that all falls were lumped together. Yet, PD patients fall for a variety of reasons, and each fall type likely has its own associated risk factors. For example, falls preceded by syncope have a very different pathophysiology and set of risk factors ${ }^{9}$ than falls that are preceded by freezing of gait $^{10}$ and a complex interplay between multiple factors is presumably involved in causing most falls. For example, falling during the night may be associated with bladder dysfunction (nycturia necessitating patients to leave their bed), orthostasis (caused by need to arise after having been recumbent for hours) and gait freezing (which is often maximal at night because of nocturnal off periods, and because many patients walk in the dark as they do not switch the lights on for fear of waking up their spouse, so they cannot visually compensate for freezing). Similarly, falling while climbing stairs may be the result of either visual problems (diminished visual acuity, visual field changes, impaired saccades, or decreased contrast vision), orthostasis (typically maximal when patients reach the top of the staircase), proximal leg weakness, or a combination thereof. An important target for future studies will be to carefully separate the different fall types, and to determine the role of motor- and nonmotor symptoms associated with each of these. These studies should best evaluate falls prospectively with sufficiently long follow-ups, and preferentially assess falls objectively at home using wearable sensors ${ }^{2}$. Also, re-usage of data collected in large PD cohorts may help to clarify fall risk factors at low costs ${ }^{11}$.

The study of Alvarado-Bolaños ${ }^{12}$ and colleagues once again underscores the complexity of falling. A better understanding of fall mechanisms, risk factors and their interactions will allow for timely referral and for personalized treatment of patients at risk, thereby reducing the devastating consequences of falling for patients with PD.

\section{References}

1. Wood BH, Bilclough JA, Bowron A, Walker RW. Incidence and prediction of falls in Parkinson's disease: a prospective multidisciplinary study. J Neurol Neurosurg Psychiatry. 2002 Jun;72(6):721-5. https://doi.org/10.1136/jnnp.72.6.721

2. Lima ALS, Smits T, Darweesh SK, Valenti G, Milosevic M, Pijl $M$, et al. Home-based monitoring of falls using wearable sensors in Parkinson's disease. Mov Disord. 2019 Aug;mds.27830. https://doi.org/10.1002/mds.27830

3. Canning CG, Paul SS, Nieuwboer A. Prevention of falls in Parkinson's disease: a review of fall risk factors and the role of physical interventions. Neurodegener Dis Manag. 2014;4(3):203-21. https://doi.org/10.2217/nmt.14.22

4. Bloem BR, Hausdorff JM, Visser JE, Giladi N. Falls and freezing of gait in Parkinson's disease: a review of two interconnected, episodic phenomena. Mov Disord. 2004 Aug;19(8):871-84. https://doi.org/10.1002/mds.20115

5. Hauser RA, Heritier S, Rowse GJ, Hewitt LA, Isaacson SH. Droxidopa and Reduced Falls in a Trial of Parkinson Disease Patients With Neurogenic Orthostatic Hypotension. Clin Neuropharmacol. 2016 Sep-Oct;39(5):220-6. https://doi.org/10.1097/WNF.0000000000000168

6. Martignoni E, Tassorelli C, Nappi G. Cardiovascular dysautonomia as a cause of falls in Parkinson's disease. Parkinsonism Relat Disord. 2006 May;12(4):195-204. https://doi.org/10.1016/j.parkreldis.2006.02.001
7. Domingos JM, Godinho C, Dean J, Coelho M, Pinto A, Bloem BR, et al. Cognitive Impairment in Fall-Related Studies in Parkinson's Disease. J Parkinsons Dis. 2015;5(3):453-69. https://doi.org/10.3233/JPD-150590

8. Bloem BR, Grimbergen YA, Cramer M, Willemsen M, Zwinderman $\mathrm{AH}$. Prospective assessment of falls in Parkinson's disease. J Neurol. 2001 Nov;248(11):950-8. https://doi.org/10.1007/s004150170047

9. Thijs RD, Bloem BR, Dijk JG. Falls, faints, fits and funny turns. J Neurol. 2009 Feb;256(2):155-67. https://doi.org/10.1007/s00415-009-0108-y

10. Nonnekes J, Snijders AH, Nutt JG, Deuschl G, Giladi N, Bloem BR. Freezing of gait: a practical approach to management. Lancet Neurol. 2015 Jul;14(7):768-78. https://doi.org/10.1016/S1474-4422(15)00041-1

11. Lord S, Galna B, Yarnall AJ, Morris R, Coleman S, Burn $D$, et al. Natural history of falls in an incident cohort of Parkinson's disease: early evolution, risk and protective features. J Neurol. 2017 Nov;264(11):2268-76. https://doi.org/10.1007/s00415-017-8620-y

12. Alvarado-Bolaños A, Cervantes-Arriaga A, Arredondo-Blanco K, Salinas-Barboza K, Isais-Millán S, Rodríguez-Violante M. Falls in persons with Parkinson's disease: do non-motor symptoms matter as much as motor symptoms? Arq Neuropsiquiatr. 2019;77(11):761-67. https://doi.org/10.1590/0004-282X20190148 